\title{
International Internet Retail Marketing: Do Product Characteristics Really Matter?
}

Leland Taylor, (Email: letaylor@sbcglobal.net), Nova Southeastern University

Bahaudin Mujtaba, (Email: Mujtaba@sbe.nova.edu), Nova Southeastern University

\begin{abstract}
Many practitioners and academic researchers are engaged in the evaluation and study of the impact of the Internet on global retail marketing. Findings have generally focused on the unique attributes of the Internet marketplace and many have discussed product attributes or characteristics which seem important to market success. However, a 2003 Irish retail study claims there are no correlations between the types of product purchased on the Internet and challenges the validity of product characteristics as an important consideration for Internet marketing (Golden, Hughes and Gallagher, 2003). This article reviews the development of product characteristic marketing theory and discusses the findings of recent studies which investigate product characteristics and their importance to Internet based international retail marketing plans.
\end{abstract}

\section{INTRODUCTION}

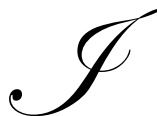

n 1912 C. C. Parlin published a classification system for consumer retail commodities (Gardner, 1945). This classification system provided a simple framework for the segregation of retail goods into classes of merchandise with common marketing characteristics. Since that time, the commodity structure has been revised and expanded, but it remains widely accepted by marketing theorists as a fundamentally useful tool for understanding and defining the general market characteristics of retail consumer goods. The Characteristics of Goods classification system, which lies at the heart of modern marketing theory, is a basic building block for the development and evaluation of marketing plans. The value that such a simple tool brings to today's Internet marketing practitioner lie in the definition of common characteristics that provide a clear roadmap for the successful market planning of consumer commodities. But are there a set of product characteristics that are important to Internet retail marketing?

As practitioners and academic researchers have been working to evaluate and define the impact of the Internet and the new Internet retail market, the findings have generally focused on the unique attributes of the ECommerce marketplace. Most of the studies accepted Characteristic of Goods Theory without empirical test. One exception is a 2003 study of Irish distributors of handicrafts and art, claiming there are no correlations between the types, or characteristics, of goods purchased on the Internet and challenges the validity of product characteristics as an important consideration for Internet marketing (Golden, Hughes, and Gallagher, 2003). Another, less direct, challenge to the validity of Characteristic of Goods Theory was raised in 2000, when Christensen and Tedlow stated that the introduction of the Internet retailing had fundamentally changed the basis for competitive advantage in retailing. As a basic marketing theory, the validity of Characteristic of Goods Theory is therefore indirectly questioned with respect to Internet retail purchases.

Changes in retail marketing techniques and adoption of Internet retailing is occurring on a global basis. Researchers are working to understand the scope of change and develop effective theoretical constructs that will help explain buyer behavior using the Internet as a new marketing channel. For example, Australian researchers have forecast dramatic increases in online retail activity by 2010 and note that over $77 \%$ of shoppers have made retail purchases over the Internet (Chang and Samuel, 2004). Changes in lifestyle have been sited as motivation for shoppers to explore new options in search of greater utility and time savings. Consumer effort and time are expended in travel to physical shopping locations, and has been noted as a source of additional utility for Internet shoppers who need to conserve their time or who dislike shopping (Davies, 1995). 
The changes occurring in consumer retailing are part of an evolutionary process where consumers seek greater utility and efficiency in the shopping process (Pandya and Nikhilesh, 2005). Other shifts in consumer retail purchasing patterns have been studied and discussed by researchers; major shifts in retail market structures caused by innovation have been called disruptions. The use of the Internet as a retailing channel is the fourth major disruption in the development of the modern retail model (Christensen and Tedlow, 2000). The prior three changes; department store retailing, mail order catalogues and discount department stores were all advances that were facilitated by social and technological change. Each of these drove change in retail marketing practices and marketing activities.

In each of the three prior disruptions, consumers benefited from greater access to products, more efficiency or lower prices and as a result of consumer acceptance, the retail market was changed. As a marketing channel, the Internet has the potential to have a similar impact, by offering consumers greater convenience, removing the need to travel to store locations, and making shopping for products available at any time. There are also benefits available to retailers in the form of lower transaction costs, an improved ability to communicate product features and lower distribution costs for products which can be digitally delivered. The combination of potential benefits to consumers and retailers, offered by Internet marketing are a compelling factor supporting the continued success and growth of the Internet as a retail marketing channel (Pandya and Nikhilesh, 2005).

Marketing professionals are learning to utilize the Internet for advertising and sale of retail products. As a result, an entirely new set of technical tools and strategies are being employed in the development of marketing plans. The use of the Internet in marketing plans should complement, differentiate, or add unique value that is not based, solely, on easily duplicated technology. Otherwise, Internet tools and features may lead to weakening of a company's competitive position by facilitating easily duplicated features and creating erosion of gross margins as competition becomes increasingly based on price (Porter 2001). But, considering the potential for both the consumer and the reseller to benefit from the use of the Internet as a retail medium, it appears certain that Internet retailing will continue to grow in popularity.

Prior to the advent of the Internet, the ability to reach mass markets on a national or international scale required extensive resources (Copeland, 1923). Larger companies enjoyed a significant competitive advantage due to their financial resources and resulting broad reach. By using the Internet, small companies can now, cost effectively, market to customers who previously were beyond their reach. The Internet is also driving disintermediation, reducing the need for distributors and middlemen, and is lowering the barriers to entry into international markets by facilitating direct order access to merchandise (Porter, 2001).

The upcoming section explores the development of classification theory. The review begins with the introduction of classification theory in 1912 and follows the development of the theory into current marketing research. The conclusions based on this literature, and the findings of research comparing current theoretical research with historical theories, provide a clear and compelling argument supporting the assumption that the fundamentals of retail marketing science; like the Characteristic of Goods Theory, have an important place within modern marketing science and provide valuable insight into current and future Internet retail market activity.

\section{REVIEW OF THE LITERATURE}

\section{Commodity Classification Theory - Copeland/Parlin}

The original consumer goods classification system defined by C. C. Parlin was primarily focused on Convenience Goods and Shopping Goods. Convenience Goods are those consumer products that are normally commodity type items that can be purchased at multiple locations and are easily accessible to the consumer. Because these items are generally very familiar to the consumer, purchasing decisions are usually related to convenience, cost, and brand. The brand of the item typically differentiates the product only in the fact that consumers are familiar with the product, its packaging, and have developed a moderate preference for that product, delivered in a particular color, or shape of package. Brand loyalty may provide some opportunity for a minor differential in the price that a consumer is willing to pay, although the amount of this differential is not generally very large. Convenience Goods are characterized by the customer's willingness to substitute another brand or type of product rather than delay need 
fulfillment for the good (Copeland, 1923). Examples of convenience goods include common grocery items, some toiletries, soaps and most paper goods. The most important factor in market planning of goods of this type is the development of a broad base of retail locations where the product may be conveniently acquired. Ready access to Convenience Goods is critical; as these items are usually purchased for immediate use (Gardner, 1945).

Shopping Goods comprise a wide range of items that include product purchases that consumers perceive to have significant importance (Gardner, 1945). The importance may be due to the value in the marginal gain to the individual of expending the effort to comparison shop for the item or in the quality of the good as perceived by the consumer (Holton, 1958). The consumer is willing to expend additional effort to compare and contrast competitive products before making a purchase decision (Copeland, 1923). Unlike Convenience Goods, the consumer will forego fulfillment of the need for the Shopping Good until the marginal level of quality and/or cost of the product are sufficient to satisfy the consumer's perception of the product's value (Holton, 1958). Typically, brand is a moderately important element among Shopping Goods as an indicator of product quality or value. Brand loyalty among consumers of a particular product can create an opportunity for a small price differential although cost or perceived consumer value is a key component of Shopping Goods. Because of the comparative nature of shopping goods, retailers of these products must be centrally located in order to draw large numbers of shoppers from a wide territory (Copeland, 1923). The distinction between Shopping Goods and Convenience Goods may lie in the marginal value perception of the consumer. Consumers that place a high value on their time or are in higher income classes may regard certain items as Convenience Goods and the same goods may be perceived by people with lower marginal value perceptions as Shopping Goods (Holton, 1958). This perceptual element in commodity classifications creates an overlap that requires marketers to have a very clear understanding of the primary market demographics of their target customer base to predict accurately, customer acceptance levels.

The retail commodity classification system was expanded by Copeland to include Specialty Goods, where price is not the primary attraction of the product; consumers are willing to make a special effort to acquire a particular product based on brand. Copeland was not the first to propose a classification system, but his system is the first to be well documented (Sheth, Gardner, Garrett, 1988). In the Specialty Goods classification, the brand of the product or the reputation of the retailer is a very important symbol to the consumer of value, quality, and/or prestige (Holton, 1958). Specialty Goods include items like electronic equipment, sporting equipment, fine jewelry, and automobiles. Within this classification of goods, "psychographic" product positioning is an important element; the customer must perceive a high marginal product value, in either owning or consuming the product.

\section{Problems With Early Commodity Classifications}

The broad variety of retail products and services offered for sale create a very complex continuum of product characteristics. These characteristics do not easily lend themselves to classification using a simple three level fixedpoint structure. Many products have overlapping characteristics or may fit into multiple classifications depending on demographic or geographic factors. For example, cow's milk may be classified as a Commodity Good in the North American and most European market areas. But in the desert regions of Africa, or the Middle East, where dairy herds are scarce; cow's milk is a Specialty Good that is handled only by certain retail merchants. To address this type of problem, the classification of goods structure was expanded and modified. The new structure changed the classification process and replaced the Commodity, Shopping, and Specialty Goods classifications with a color spectrum that extends from yellow to red and includes a defined set of criteria that are used to define the classification of a good. This spectrum eliminates the need to force fit a good into a particular fixed classification or to attempt to reclassify a product based on consumer demographics. This revision of classification theory, developed in 1956 by Leo Aspinwall, represented a shift in thought and gave marketing practitioners an improved set of tools to evaluate market activity, which included new characteristics to consider.

\section{Characteristics Of Goods - Aspinwall}

Aspinwall's Characteristics of Goods Theory asserts the presence of five key attributes of a product; Replacement Rate, Gross Margin, Adjustment, Time of Consumption and Search Time. The theory establishes a model that can be used to evaluate the attributes of a product and thereby evaluate the proper market and distribution 
strategy for that product. The Characteristics of Goods Theory is an expansion of the earlier works of C. C. Parlin and Melvin T. Copeland. The classification structure utilizes a continuous color spectrum from yellow to red rather than the distinct classification strata used by Copeland and Parlin. However, Aspinwall's theory does employ three primary colors and these colors align with Copeland's three product classes.

Table 1: Characteristic Of Goods Classifications

\begin{tabular}{|l|c|c|c|}
\hline \multicolumn{1}{|c|}{ Characteristics } & Red Goods & Orange Goods & Yellow Goods \\
\hline Replacement Rate & High & Medium & How \\
\hline Gross Margin & Low & Medium & High \\
\hline Adjustment & Low & Medium & High \\
\hline Time of Consumption & Low & Medium & High \\
\hline Searching Time & Low & Medium & \\
\hline
\end{tabular}

The scaled approach was developed to simplify the classification of goods and to facilitate the development of a mathematical model. To aid with the definition of a product characteristic, three rules were followed: 1) the characteristic must be applicable to every product; 2) each characteristic must be measurable; and 3) every characteristic must be logically related to all other characteristics. Using these rules, five general characteristics were identified that were used to determine the product characteristics.

Replacement rate: The Replacement Rate is the relative cycle time for the replacement of the product, as measured by the time between repurchases or "The rate at which a good is purchased and consumed by users in order to provide the satisfaction of a need the consumer expects from the product" (Aspinwall, 1956). The replacement rate of a product is a relative measure that depends upon the consumer and varies from consumer to consumer. For example, people consume bread and milk at differing rates. However, these goods have a High replacement rate when compared to furniture, appliances or automobiles. For the purposes of this theory, it is important to note that replacement rate is a measure of the repurchase cycle and not the actual consumption of the product. Since, consumers repurchase some types of items before they have fully consumed the original product. For example, new clothing purchases are often made before previously purchased clothing items have reached the end of their useful life.

Gross margin: The total gross margin that each product is capable of generating is a key characteristic because it actually determines if the product will be marketed. The marginal value that each product can create is similar to electrical potential or voltage (Aspinwall, 1956). If insufficient potential exists to overcome the resistance or cost of manufacture and distribution, there will be no product flow in the market. As noted in Table 1, gross margin is inversely related to replacement rate. Higher replacement rate items may be successfully marketed with lower gross margins because the higher turnover allows sufficient margin to be generated to pay for marketing and distribution costs.

Adjustment: Adjustment measures of the amount of service or transformation that a good requires to meet the exact need of the end customer. All products require some level of adjustment from their raw state to become a finished product that meets customer requirements. For example, milk is packaged in a specific container size and is available in low fat, skim and whole varieties. The amount of Adjustment in a product is usually inversely related to the Replacement Rate and Gross Margin. High Replacement Rate products tend to require very little Adjustment due to the low amount of Gross Margin available.

Time of consumption: This characteristic is defined as "The measured time of consumption during which the good gives up the utility desired." This measure is strongly correlated to Replacement Rate but is a necessary supplement because some products with short consumption times are repurchased at specific rates unrelated to consumption. An example would be fireworks, which are consumed very quickly but are typically repurchased only once or twice per year for holiday events. Also medicines and service-type products are consumed quickly, but tend to be purchased at irregular intervals when the consumer has a specific need. 
Searching time: Aspinwall's original definition of search time, "The measure of average time and distance from the retail store," cleanly conveys the concept behind the search time characteristic of a product. However, with the advent of the Internet as a product distribution medium, the search time definition needs to be related to the point of sale and time from recognition of a need to fulfillment of the need rather than a physical retail location.

Figure 1: Characteristics Of Goods Classification Chart

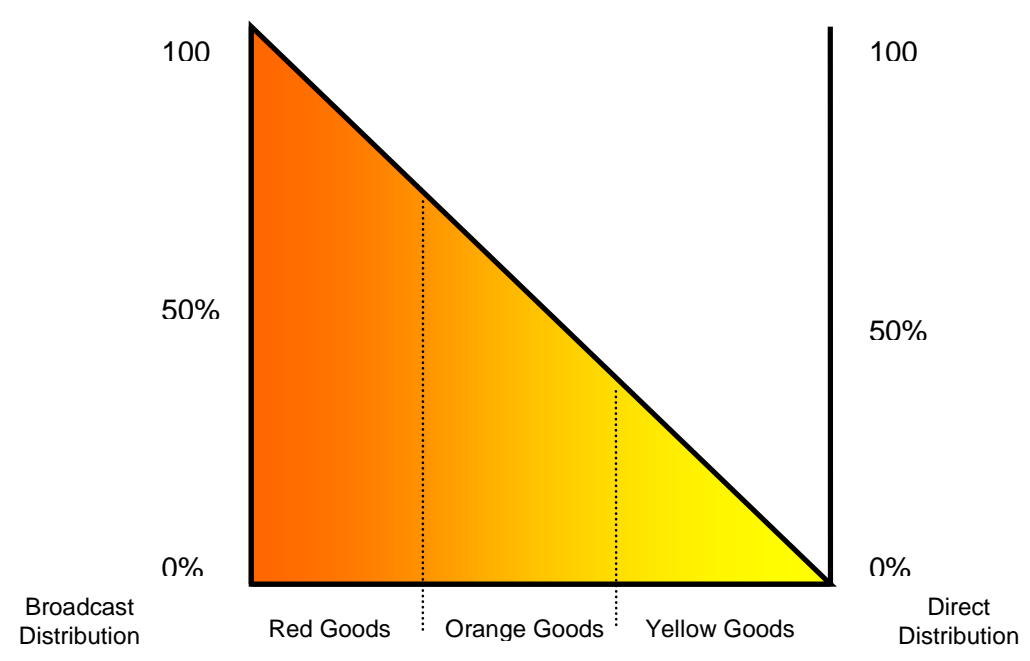

Aspinwall also segmented goods based upon the distribution methods that were used for the product. According to his theory the distribution of a product varied based on the characteristics of the product. Therefore, goods could be classified in different groups by observing the type of distribution model that is employed to market the product.

The chart shown in Figure 1 demonstrates the relationship of Red, Orange and Yellow Goods to the types of distribution method utilized. The chart shows the scale that ranges between pure Red Goods at the extreme left portion of the scale, which in the purest form are distributed $100 \%$ by Broadcast type distribution methods and pure Yellow Goods on the other extreme are distributed 100\% via direct distribution processes. The definition of "Broadcast" distribution, for the chart above, includes most indirect methods of distribution that involve wholesalers, brokers and retail channels. By evaluating the percentage of sales that are sold in direct versus broadcast methods, a point on the horizontal axis of the chart can be determined. The scale of the horizontal axis is zero to one hundred percent in terms of direct distribution. If a product is distributed $15 \%$ by direct distribution, it falls into the classification of a Red product.

One additional note concerning the placement of products on the chart; product placement tends to shift in the Red direction as the product matures during its lifecycle. The cost of manufacturing, technological content and overhead costs of a product normally trend downward for maturing products resulting in a "Red" shift and may require adjustment in marketing strategy later in a product's life.

\section{Characteristics Of Goods - Bucklin}

The research into the classification of goods was expanded in 1963 when Bucklin proposed a change in the classification of goods. His classification used the traditional terms; Convenience Goods, Shopping Goods, and Specialty Goods. But the classification of the goods was based on a problem solving concept, that supposed that the customer was acquiring goods to fulfill a need and that the process of comparing goods in the market, or shopping, 
was a result of the importance of the purchase to the customer and the experience and information available to the customer. In his redefinition of the system, Bucklin argued that there were shopping goods and non-shopping goods. The difference between the two groups was largely based on the amount of information that the customer had about the products. In the case of non-shopping goods, like Convenience Goods, the consumer knows the market price and is usually familiar with the product. Specialty items are also non-shopping goods; the consumer believes only one particular brand or type of product will fulfill his or her need. Therefore, consumers will bypass substitute products and forego the comparison process of shopping to acquire the one product that meets their perceived needs.

In addition to changing the definitions of the Characteristics of Goods, Bucklin also introduced the concept of "Patronage Motives" and the classification of retail stores based on them. Stores were classified as Convenience Stores, Shopping Stores, and Specialty Stores. Convenience Stores are those where the consumer has a definite product preference and seeks products to meet that preference from the most accessible store. Shopping Stores are those stores that the consumer will utilize when he or she does not have a completely defined preference for the product, and will shop in these stores to gain information to complete the product preference. Specialty Stores are those stores consumers will seek for a particular good, even though the store may not be the most accessible. By combining the Characteristics of Goods and the three classifications of stores based on Patronage Motives, Bucklin expanded the research into the classification of goods and consumer shopping motivation by creating nine different market categories:

- $\quad$ Convenience Store/Convenience Good: Consumer prefers to buy a readily available brand of product at the most readily available location.

- $\quad$ Convenience Store/Shopping Good: Consumer selects the product from an assortment at the most readily available location.

- $\quad$ Convenience Store/Specialty Good: The consumer purchases a specific brand of product from the most readily available location.

- $\quad$ Shopping Store/Convenience Good: The consumer is indifferent to the brand of product, but shops to gain a lower price or better service.

- $\quad$ Shopping Store/Shopping Good: The consumer compares products to identify the best value proposition based on price, brand, and service.

- $\quad$ Shopping Store/Specialty Good: The consumer has a strong preference for a particular brand of a particular product, but shops between several stores to get the best service and price for a specific brand.

- $\quad$ Specialty Store/Convenience Good: The consumer prefers to trade at the specific store but is indifferent to the brand of product purchased.

- $\quad$ Specialty Store/Shopping Good: The consumer prefers to trade at a particular store but shops among an assortment of brands to select the good he or she will purchase.

- Specialty Store/Specialty Good: The consumer has a preference for both the particular store and the particular product.

As with physical store locations, consumers develop preferences for particular Internet sites. This can be due to prior experience with the site, recommendations from peers, or other factors. The type of channel selected by a consumer is often dependent upon the characteristics of the product; consumers prefer to personally inspect or experience some goods prior to purchase (Peterson, Balasubramanian, and Bronnenberg 1997). It is apparent from the list above that considering patronage motives and the characteristics of goods provides a richer view of the market. Loyalty to a particular reseller or resale channel can be an effective segmentation mechanism (Peterson et al., 1997). By considering the combination of patronage motives with other characteristics of goods a marketing practitioner gains a greater understanding of the potential market performance of a product and can make adjustments in the marketing plan to optimize the potential for success. The work of Bucklin in regard to patronage motives is an important evolutionary change in thought regarding product characteristics; expanding from the physical characteristics of the product, to the whole purchase experience and customer psychological, perceptions and preferences. 


\section{Characteristics Of Goods - Miracle}

The Characteristics of Goods classifications were expanded again in 1965 by Gordon Miracle. He found the traditional classifications too narrow and rigid, and Miracle believed an extension was necessary to include what he referred to as the "Total Product." This "Total Product" definition included the entire bundle of utilities, or the sum total of benefits that the consumer gained from the purchase of the product (Miracle, 1965). The product bundle includes the tangible product and the intangible utilities of retail location, product selection, price, market characteristics, and consumer characteristics. According to Miracle, "The nature of the product determines how much time (or what kinds of effort) consumers will wish to spend in buying the product. Thus, consumer and market characteristics may be described in terms of product classifications." Within Miracle's classification structure, nine product characteristics were included:

- $\quad$ Unit value: The value of each product is a key consideration in the market planning of a product. The unit value may be low, as in the purchase of bread or milk, or it may be very high, like automobiles, jewelry or real estate. The unit value of the product is a key factor in the time that a consumer will devote to research or comparative shopping of a product.

- $\quad$ Significance of each individual purchase to the consumer: Beyond unit price, some purchases have a special significance to the consumer. The customer's desire for the product and the importance of the product to him are an important consideration. The significance of purchase to a consumer may relate to the monetary value of the purchase or the fulfillment of some special need that is unique to a particular group of consumers. For example, collectors often place high value on goods that have little use or appeal to other consumers.

- $\quad$ Time and effort spent purchasing by consumers: The time that a consumer is willing to devote to the acquisition of a product is often a reflection of the value of that product to the consumer. Commodity items with a low value are most often purchased with little search and only the minimum required effort.

- $\quad$ Rate of technological change (including fashion changes): The rate of technological change of a product often dictates the replacement rate of the product. Products with high rates of technological change or fashion changes may be replaced by a consumer before the product has reached the end of its functional life.

- $\quad$ Technical complexity: Highly complex technical products usually require some type of special technical sales or after sales support. These products may appeal to a relatively narrow segment of the consumer market. The consumers who require these products will look to the retailer as a source of technical information regarding the product and its application. This information dependency often creates special circumstances that the marketer must consider. It also can create situations where additional, services or service related products can be bundled with the product.

- $\quad$ Consumer need for service (before, during, or after the sale): The consumer need for service is often related to the technical complexity of the product. By understanding the consumer's need for service related to a product is an important consideration because of the cost of delivery of those services and the marketer's ability to meet the demand for the service will impact the overall bundle of utility that the consumer perceives and will influence his purchasing decision.

- $\quad$ Frequency of purchase: Products and services with a high frequency of purchase generally must be easily available. Therefore, evaluating the frequency of purchase is an important characteristic to consider.

- $\quad$ Rapidity of consumption: On the surface it may seem that rapidity of consumption and frequency of purchase are the same characteristic. However, the frequency of purchase differs from the rapidity of consumption in a significant way. Products with rapid consumption cycles like, diary products and produce are repurchased at or very near the point where the product is totally consumed. This may not apply to some products, such as clothing. Clothing is a frequently purchased item but repurchase of replacement articles may occur well before the initial product is totally consumed.

- $\quad$ Extent of usage: This characteristic refers to the number and variety of consumers and variety of ways in which the product provides utility. Products with a broad appeal, which are used by large populations of consumers, are marketed differently than products with narrow consumer interest and application. Items like industrial capital equipment may have only one purpose and fit the requirements of only a few consumers.

The nine characteristics proposed by Miracle were related to the characteristics proposed by Aspinwall and were classified using a scaled approach that ranged from "Very Low" to "Very High." There were five increments on 
the scale used to classify each of the characteristics; Very Low, Low, Medium, High, and Very High and five product groupings defined, Groups 1-5, although Miracle stated that a continuum would be more appropriate; he used the groups for simplicity. Group 1 products relate to "Red Goods" on Aspinwall's scale and Group 5 products to "Yellow Goods," with Group 2 through Group 4 being "Orange Goods." Like prior classification structures, a product characterized using Miracle's scale could change over time as consumer became more familiar with the product or as the need for the product or service diminished over time. Classification measurement using Miracle's system was subject to the perception of the evaluator. The classifications also lacked well defined measurement criteria, which resulted in the classifications being somewhat arbitrary and imprecise. Therefore, the usefulness of Miracle's contribution has been somewhat limited.

\section{Characteristics Of Goods \& Internet Marketing}

Characteristics of Goods Theory was updated, in 1997, when the consumer's desire to experience some products prior to purchase was identified as a characteristic that was an important consideration, especially in light of the growing availability of intangible goods available for sale over the Internet. The Internet provides a rich medium to communicate product information, promotional data, specifications and the visual attributes of a product (Porter 2001). However, some consumers prefer to physically evaluate certain products prior to their acquisition.

"Experience" Goods are those products that the consumer prefers to experience or physically inspect prior to purchase. If the product is music or, a CD, the Internet environment offers the ability for consumers to sample the product prior to purchase. However, if the product is a new perfume the Internet will not be a good fit to the needs of first time buyers who will want to experience the fragrance of the product. Once a consumer develops a brand preference items like perfume may be successfully marketed over the Internet. If a customer must experience the good prior to purchase, the selection of the Internet as a major marketing channel is typically not advisable unless the attributes of the Internet allow the appropriate experience to be transmitted to the consumer.

Search goods are typically evaluated by consumers through comparison of product information or specifications. If a Search good can be effectively evaluated, by consumers, through the comparison of product information it is likely to be a good fit for Internet retailing due to the information storage and search capabilities of the Internet (Peterson et al., 1997).

According to the work of Peterson et al. low cost products that are purchased frequently, with a value proposition based largely on tangible (or physical) attributes are not well suited to retail marketing via the Internet. The characteristics of a product are a key determinate in the successful marketing of a product over the Internet (Peterson, et al., 1997). Along with the considerations of search versus experience goods, the evaluation of product characteristics should include an examination of three dimensions:

- $\quad$ Cost and frequency of purchase: The cost and the frequency of purchase of a product are important considerations because of the relationship of the distribution structure required to support the product in the market. Frequently purchased low cost, commoditized items often require immediate delivery to the consumer. Where as, high cost infrequently purchased items usually require a completely different distribution and transaction structure. Therefore, consideration of the cost and frequency of purchase characteristics of a product are important considerations due to the associated overhead requirements of the marketing model.

- Value proposition: The value proposition of a product relates to the type of value intrinsic to the product. The value proposition of a product varies along a continuum, from tangible physical products, to intangible digital and service products. The Internet is particularly well suited to the marketing and delivery of intangible products. Intangible products, with higher rates of purchase, are proportionately better suited to marketing over the Internet than infrequently purchased tangible products (Peterson et al., 1997). Examples of products, with high rates of purchase that are physically intangible are tickets and stock quotations. Each of these products can be delivered electronically as digitized services.

- $\quad$ Product differentiation: The characteristic of differentiation refers to the ability of the seller to create a sustainable competitive advantage. The Internet has the potential to spawn intense price competition for 
products with little differentiation (Porter, 2001). A strong and sustainable element of product differentiation will translate to consumer value that and will allow sellers to maintain price points within the competitive marketplace.

- Internet retail marketing is a small, but growing, segment of consumer retail activity. Therefore, the evaluation of Internet retailing should be conducted from a perspective that includes conventional retail marketing channels. The characteristics of the Internet as a retail channel are a complimentary extension of the conventional market. The Internet has some unique characteristics which do not exist in other channels but the evaluation of Internet retail marketing needs to be performed in light of the whole conventional market for the results to be meaningful (Peterson et al., 1997). The important characteristics of the Internet as a marketing channel are:

- $\quad$ The ability to store large amounts of information inexpensively

- The ability to easily organize and search large amounts of information.

- The ability to of the Internet to allow consumers to obtain specific information on demand

- The ability of the Internet to provide high quality visual representations of products that are superior to printed matter

- $\quad$ The ability of the Internet to serve as a transaction medium

- $\quad$ The ability to distribute digital products and services

- $\quad$ The relative low cost of establishing a retail outlet on the Internet

These attributes and the three dimensions are closely aligned to the characteristics that that were described by Miracle and are a consistent extension of characteristics of goods theory. The figure below is an example of a Product and Service Classification Grid (Figure 2) with some general product types included. The grid combines the three dimensions and how they relate to specific products. The result is an easy to understand classification matrix. It is important to note that the dimensions are a continuum and not fixed measurements therefore, the application of the grid to real product marketing situations requires interpretation by the practitioner.

Figure 2: Product And Service Classification Grid

\begin{tabular}{|c|c|c|c|}
\hline Dimension 1 & Dimension 2 & Dimension 3 & $\begin{array}{c}\text { Examples of Products and } \\
\text { Services }\end{array}$ \\
\hline \multirow{4}{*}{$\begin{array}{l}\text { Low outlay, frequently } \\
\text { purchased goods }\end{array}$} & \multirow{2}{*}{$\begin{array}{l}\text { Value proposition, Tangible } \\
\text { or Physical }\end{array}$} & "Differentiation potential High & Wines, Soft drinks, cigarettes \\
\hline & & Differentiation potential Low & Milk, eggs \\
\hline & \multirow{2}{*}{$\begin{array}{l}\text { Value proposition, } \\
\text { intangible or informational }\end{array}$} & Differentiation potential High & $\begin{array}{l}\text { On-line newspapers and } \\
\text { magazines }\end{array}$ \\
\hline & & Differentiation potential Low & Stock market quotes \\
\hline \multirow{4}{*}{$\begin{array}{l}\text { High outlay, infrequently } \\
\text { purchased goods }\end{array}$} & \multirow{2}{*}{$\begin{array}{l}\text { Value proposition, Tangible } \\
\text { or Physical }\end{array}$} & Differentiation potential High & Stereo systems, automobiles \\
\hline & & Differentiation potential Low & $\begin{array}{l}\text { Precious metal ingot of } \\
\text { known weight and purity }\end{array}$ \\
\hline & \multirow{2}{*}{$\begin{array}{l}\text { Value proposition, } \\
\text { intangible or informational }\end{array}$} & Differentiation potential High & Software packages \\
\hline & & Differentiation potential Low & $\begin{array}{l}\text { Automobile financing, } \\
\text { insurance }\end{array}$ \\
\hline
\end{tabular}

\section{Alta Vista Corporation Study}

In 2000, Alta Vista Corporation surveyed its global customer base concerning Internet retail purchasing activity. One of the goals of this survey was to discover if there were particular product types or user demographics that related to success in the Internet retail environment. The raw database of information from that study encompassed over 750,000 responses from a global population of Internet users. The survey asked respondents to identify the types of purchases that they made over the Internet. Internal validity of the survey was evaluated and a Cronbach Alpha of 0.79 was reported. The population of total Internet users at the time of the survey was not 
established therefore it is unclear if the 750,000 responses to the Alta Vista survey represent a statistically valid measure. Although, considering the random nature of the survey process, the global audience, and enormous volume of responses collected, the Central Theorem states that the results should approximate the mean of the population.

A sample of the findings of the Alta Vista Survey is shown in Table 2. The survey responses were evaluated using Spearman's rho non-parametric correlation test; statistically significant correlations were found between all variables at the 0.01 level. This supports an argument favoring the existence of relevant characteristics among the products. Otherwise, the reported purchases would have shown no correlation.

\section{CONCLUSION}

The simple premise of classification theory is: there are a bundle of attributes or characteristics, unique to particular products that are important determinates of the market channels appropriate for the product. Early classification theory focused on product attributes relating to customer value perception and product differentiation. During the development of classification theory, consumer experience, attitude and perception were explored and considered key elements. Current classification theory expands upon the base knowledge of the past and includes elements that relate to the new generation of service and digital products that have emerged with the development of the Internet.

Table 2: Alta Vista Survey - Reported Purchases

\begin{tabular}{|l|c|c|}
\hline \multicolumn{1}{|c|}{ Variable } & Frequency & Percentage \\
\hline Books & 180120 & 23.7 \\
\hline Clothing and Accessories & 140063 & 18.4 \\
\hline Computers and Electronics & 154934 & 20.3 \\
\hline Groceries and Gourmet & 88802 & 11.7 \\
\hline Home and Garden & 94195 & 12.4 \\
\hline Office Supplies and Furniture & 99999 & 13.1 \\
\hline Pet Supplies & 76206 & 10 \\
\hline Software and Games & 157683 & 20.7 \\
\hline Sporting Goods & 101405 & 13.3 \\
\hline Toys and Baby Gear & 81771 & 10.7 \\
\hline Never Purchased & 139894 & 18.4 \\
\hline
\end{tabular}

Retailers need to make a careful evaluation of the "Suitability" of a product to the on-line retail environment prior to marketing that product over the Internet (Doolin, McLeod, McQueen, and Watton, 2003). The "Suitability" of the Internet for a marketing channel is dependent upon the characteristics of the products and services being marketed (Peterson et al., 1997). The key product characteristics, according to current classification theory are: the type of good (search or experience), the cost and frequency of purchase, the value proposition of the product (tangible or intangible), and the degree of differentiation. The characteristics of the Internet as a marketing channel are unique, and to assure successful marketing, products should be well fit to the characteristics of the on-line environment.

The proper "fit" of a product to the Internet marketing environment can be evaluated by examining the characteristics of a product and comparing them to the characteristics of the Internet as a marketing channel. Products with characteristics that effectively leverage Internet attributes should have a marketing advantage in the Internet environment when compared to traditional retail sales methods.

The Internet is a "Discontinuity" (Peterson et al., 1997; Christensen and Tedlow, 2000; and Doolin et al., 2005) and has significantly changed marketing trends by offering a new channel with new characteristics. Fundamental theories like the Characteristics of Goods continue to serve a meaningful purpose at the core of Marketing Theory and help to explain retail purchasing behavior. Clearly, there are ample theoretical constructs, from various authors who support the relevance of product characteristics to Internet retail marketing. The theories of these scholars are also supported by data, as demonstrated in the Alta Vista survey of 2000. Therefore, based on the 
preponderance of information available, product characteristics must be considered an important element within the marketing planning process.

\section{REFERENCES}

1. Aspinwall, L. (1961). Four marketing theories, Commemorative Collection, University of Colorado; Bureau of Business Research, 1-46.

2. Bucklin, L. (1963). Retail strategy and the classification of consumer goods, Journal of Marketing, 27(1), 5055 .

3. Bucklin, L. (1965). Postponement, speculation and the structure of distribution channels, Journal of Marketing Research, 2(1), 26-31.

4. Bucklin, L. (1966). Testing the Propensities to Shop, Journal of Marketing, 30, 22-27.

5. Chang, J., Samuel, N. (2004). Internet shopper demographics and buying behavior in Australia, Journal of American Academy of Business, 5(1), 171-176.

6. Christensen, C. and Tedlow, R. (2000). Patterns of disruption in retailing, Harvard Business Review, 78(1), $42-45$.

7. Copeland, M. (1923). Relation of consumer buying habits, Harvard Business Review, 1(1), 282-289.

8. Davies, G. (1995). Bringing stores to shoppers - not shoppers to stores, International Journal of Retail and Distribution Management, 23(1), 18-23.

9. Doolin, B., McLeod, L., McQueen, B., and Watton, M. (2003). Internet strategies for established retailers: Four New Zealand case studies, Journal of Information Technology Cases and Applications, 5(4), 3-20.

10. Gardner, E. (1945). Consumer goods classification, Journal of Marketing, 275-276.

11. Golden, W., Hughes, M., and Gallagher, P. (2003). On-line Retailing: What drives success? Evidence from Ireland, Journal of End User Computing, 15, 3, 32-44.

12. Holton, R. (1958). Distinction between Convenience Goods, Journal of Marketing, 23, 53-56.

13. Miracle, G. (1965). Product Characteristics and Marketing Strategy, Journal of Marketing, 29(1), 18-24.

14. Pandya, A. and Nikhilesh, D. (2005). Conceptualizing B2C businesses as a new category of services, Journal of Electronic Commerce in Organizations, 3(1), 1.

15. Pandya, A. and Nikhilesh, D. (2005). B2C Failures: Toward an innovation theory framework, Journal of Electronic Commerce in Organizations, 3(2), 68.

16. Peterson, R., Balasubramanian, S., and Bronnenberg, B. (1997). Exploring the implications of the Internet for consumer marketing, Academy of Marketing Science Journal, 25(4), 329-346.

17. Porter, M. E. (1996). What is Strategy, Harvard Business Review, 74(6), 61.

18. Porter, M. E. (2001). Strategy and the Internet, Harvard Business Review, 79(3), 62-78.

19. Sheth, J., Gardner, D., and Garrett, D. (1998). Marketing theory: Evolution and evaluation, New York: John Wiley and Sons, 1-10. 


\section{NOTES}

